\title{
Atributos químicos do solo e produtividade da soja após milho, braquiária e feijão- caupi em latossolo na região do cerrado
}

\author{
Luan Marlon Ribeiro ${ }^{1}$, Willian Daniel de Souza ${ }^{2}$, Gessí Ceccon ${ }^{3}$ \\ Universidade Federal da Grande Dourados - UFGD, MS. ${ }^{2}$ Faculdade Anhanguera de Dourados - Anhanguera, \\ Dourados, MS. ${ }^{3}$ Embrapa Agropecuária Oeste - CPAO, Dourados, MS. E-mail: luanmarlon@hotmail.com
}

\begin{abstract}
Resumo
Objetivou-se avaliar os atributos químicos do solo e os componentes de produtividade da soja após milho, braquiária e feijão-caupi em latossolo na região do Cerrado. O experimento foi realizado na área experimental da Embrapa-CPAO em Dourados-MS, no ano agrícola de 2014/15, em Latossolo Vermelho distroférrico de textura argilosa, sob Sistema de Plantio Direto (SPD). O delineamento experimental foi em blocos casualizados com parcelas subdivididas, com quatro repetições. As avaliações químicas do solo, foram realizadas em estádio R1 da soja, sendo considerado como parcela principal os cultivos de outonoinverno (Brachiaria ruziziensis, milho safrinha, consórcio de milho com $B$. ruziziensis e feijão-caupi) e as subparcelas as profundidades do solo (0-10; 10-20; 20-30 e 30-40 cm). Para os componentes de produtividade da soja, considerou-se como parcela principal os cultivos de outono-inverno e as subparcelas as cultivares de soja (BRS 284 e BRS 360 RR). De modo geral, as culturas antecedentes a soja em SPD, proporcionaram maiores teores de alguns nutrientes em profundidade de 0 a $10 \mathrm{~cm}$, além da maior capacidade de troca de cátions, saturação por bases e matéria orgânica do solo. $O$ feijão-caupi, milho safrinha e $B$. ruziziensis proporcionaram condições para a maior produtividade da soja. A BRS 284 apresentou maior número de grãos por planta, no entanto a BRS 360 RR demonstrou ser mais produtiva.
\end{abstract}

Palavras-chave: cultivares; fertilidade do solo; integração lavoura-pecuária.

Soil chemical attributes and soybean productivity after mayze, brachiaria and cowpea in oxisol at Cerado region

\begin{abstract}
The objective of this study was to evaluate soil chemical attributes and yield components of soybean after maize, brachiaria and cowpea in an oxisol in the Cerrado region. The experiment was carried out at Embrapa-CPAO experimental area in Dourados-MS, Brazil, in the 2014/15 crop year, in a clayey dystroferric Red Latosol under no-tillage system (SPD). The experimental design was in randomized blocks with split plots with four replications. The soil chemical evaluations were carried out in soybean R1 stage, being considered as the main plot the fall-winter crops (Brachiaria ruziziensis, safrinha corn, intercropping with $B$. ruziziensis and cowpea) and the subplots as soil depths $(0-10 ; 10-20 ; 20-30$ and 30-40 cm). For soybean yield components, fall-winter crops and subplots were soybean cultivars (BRS 284 and BRS 360 RR). In general, previous soybean crops in SPD provided higher contents of some nutrients at depths from 0 to 10 $\mathrm{cm}$, in addition to higher cation exchange capacity, base saturation and soil organic matter. Cowpea, safrinha corn and B. ruziziensis provided conditions for higher soybean yield. BRS 284 presented higher number of grains per plant, however BRS 360 RR proved to be more productive.
\end{abstract}

Keywords: cultivars; soil fertility; livestock farming integration. 


\section{Introdução}

O Brasil é o segundo maior produtor mundial de soja e, durante a safra 2018/2019 a produção brasileira foi de 118.800 milhões de toneladas, já em Mato Grosso do Sul, a média produtiva foi de $3.200 \mathrm{~kg} \mathrm{ha}^{-1}$ (CONAB, 2019). No entanto, o estado possui baixas coberturas do solo pelo uso inadequado do Sistema Plantio Direto (SPD), o que facilita a degradação do solo e consequentemente a diminuição da produtividade das culturas em sucessão (BRUGGEMANN, 2011). A alternância de culturas faz-se necessária para viabilizar os sistemas de produção e potencializar seus efeitos benéficos sobre a produção agropecuária, visando a manutenção da umidade, melhoria na estrutura física e química, maior acúmulo de matéria orgânica e maior produtividade das culturas cultivadas nesse sistema (CHIODEROLI et al., 2012).

Dentre os sistemas agrícolas, podemos citar no SPD, a Integração Lavoura-Pecuária (ILP) e a Integração Lavoura-Pecuária-Floresta (ILPF), que são exemplos que destacam-se por possibilitar, de modo sustentável, uma maior produção por área através do manejo de culturas consorciadas em sucessão a rotações de outras culturas, potencializando os efeitos sinergéticos entre as espécies vegetais e a criação de animais, além de auxiliar nas interações biológicas entre os cultivos agrícola, árvores e animais, mantendo ou elevando os estoques de matéria orgânica quando comparado com outros modelos agrícolas (BALBINO et al., 2011; SILVA et al., 2016).

Porém, em regiões tropicais, um grande desafio para a manutenção são as altas taxas de decomposição do material vegetal, o que demanda por grandes quantidades de palha (CHIODEROLI et al., 2012), devendo-se considerar a utilização de gramíneas e leguminosas, anuais ou semiperenes para essa finalidade (CARNEIRO et al., 2008). Assim, a utilização de plantas com sistemas radiculares capazes de explorar diferentes profundidades do solo, com potencial diferenciado de ciclagem, proporciona melhor equilíbrio dos nutrientes e na atividade biológica do solo (CHIODEROLl et al., 2012).

Assim, salienta-se que os resíduos vegetais produzidos pelos sistemas integrados no manejo do solo influenciam positivamente na reciclagem de nutrientes e nos teores de matéria orgânica, permitindo maior produção de grãos por hectare ao produtor do que o monocultivo (COSTA et al., 2012; SILVA et al., 2016).

Considerando a necessidade do aprimoramento dos sistemas agrícolas visando potencializar os componentes de produção da soja, objetivou-se com este trabalho avaliar os atributos químicos do solo e os componentes de produtividade da soja após milho, braquiária e feijão-caupi, cultivados no outono-inverno.

\section{Material e Métodos}

O trabalho foi realizado na área experimental da Embrapa Agropecuária Oeste $\left(22^{\circ} 13^{\prime} \mathrm{S}\right.$ e $54^{\circ} 48^{\prime} \mathrm{W}, 480 \mathrm{~m}$ de altitude) em Dourados-MS durante o ano agrícola 2014/15. O solo foi classificado como Latossolo Vermelho Distroférrico de textura muito argilosa (SANTOS et al., 2018). A análise química do solo foi realizada em 2013 na profundidade de $0-20 \mathrm{~cm}$, apresentando os seguintes resultados (SILVA, 2009), $\left(\right.$ Mehlich $\left.^{-1}\right)$ ): $\mathrm{pH} \mathrm{H}_{2} \mathrm{O}=6,2 ; \mathrm{pH} \mathrm{CaCl}_{2}=5,3$; $\mathrm{V} \%=79,3 ; \mathrm{H}+\mathrm{Al}=3,94 \mathrm{cmol}_{\mathrm{c}} \mathrm{dm}^{-3} ; \mathrm{CTC}=14,19$ $\mathrm{cmol}_{\mathrm{c}} \mathrm{dm}^{-3} ; \mathrm{MO}=37,9 \mathrm{~g} \mathrm{~kg}^{-1} ; \mathrm{P}=57,3 \mathrm{mg} \mathrm{dm}^{-3} ; \mathrm{K}$ $=1,0 \mathrm{cmol}_{\mathrm{c}} \mathrm{dm}^{-3} ; \mathrm{Ca}=6,5 \mathrm{cmol}_{\mathrm{c}} \mathrm{dm}^{-3} ; \mathrm{Mg}=2,8$ $\mathrm{cmol}_{c} \mathrm{dm}^{-3}$ e $\mathrm{Al}=2,7 \mathrm{cmol}_{\mathrm{c}} \mathrm{dm}^{-3}$.

A área experimental é manejada em SPD há 15 anos num esquema de sucessão de culturas há sete anos em que, no outono-inverno é cultivado Brachiaria ruziziensis, milho safrinha, consórcio de milho com $B$. ruziziensis e feijãocaupi (var. guariba), com a soja no verão. Houve pastejo por animais nos tratamentos $B$. ruziziensis a partir de abril e no consórcio milho $\operatorname{com} B$. ruziziensis após a colheita do milho, em julho, reproduzindo um esquema de Integração Lavoura-Pecuária (ILP) nesses tratamentos.

O clima da região é classificado como Am (Tropical Monçônico) com verões quentes e invernos secos, temperaturas máximas e chuva excedente nos meses de dezembro e janeiro e temperaturas mínimas e déficit hídrico entre maio e agosto, com precipitação média anual de $1.469 \mathrm{~mm}$, segundo a classificação de Koppen (SANTOS; SILVA, 2012). Os dados de precipitação e temperaturas durante o experimento foram obtidos na Estação Meteorológica da Embrapa Agropecuária Oeste, a $300 \mathrm{~m}$ da área experimental (Figura 1). 
Figura 1. Valores quinzenais de precipitação pluvial, temperaturas máximas e mínimas registradas durante o cultivo da soja-verão 2014/15, em Dourados-MS. Fonte: Embrapa (2015).

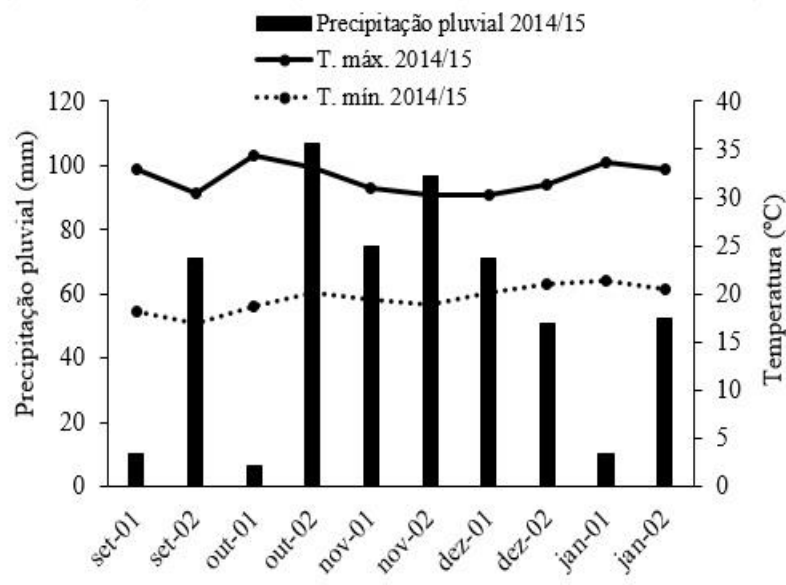

Para as avaliações dos atributos químicos do solo, o delineamento experimental foi em blocos casualizados com quatro repetições em parcelas subdivididas, as parcelas foram constituídas por quatro cultivos de outonoinverno (Brachiaria ruziziensis (B), milho safrinha $(\mathrm{M})$, consórcio de milho com $B$. ruziziensis $(\mathrm{M}+\mathrm{B})$ e feijão-caupi (var. guariba) (C)) e as subparcelas pelas profundidades do solo $(0-10 ; 10$ - 20; 20 30 e $30-40 \mathrm{~cm}$ ). Já em relação as avaliações dos componentes de produtividade da soja, também foi em blocos casualizados com quatro repetições em parcelas subdivididas, em que as parcelas foram considerados os cultivos de outonoinverno ( $B ; M ; M+B$ e $C$ ), e as subparcelas as cultivares de soja (BRS 284 e BRS 360 RR).

As coletas de solo foram realizadas entre os dias 23 e 27/11/2014 (estádio R1 da soja), onde contituiram-se de três trincheiras abertas de 1,0 $\times 0,4 \mathrm{~m}$ em cada parcela principal, entre a divisa das duas cultivares de soja. Foram retiradas amostras de cada profundidade (0 - 10; 10 - 20; $20-30$ e $30-40 \mathrm{~cm}$ ), e levadas para análise química no laboratório de solos, tecidos vegetais e corretivos, da Embrapa Agropecuária Oeste, segundo a metodologia descrita por Silva (2009).

Com relação aos componenetes de produtividade, a soja foi semeada no dia 09/10/2014, em parcelas de sete linhas com seis metros de comprimento, em espaçamento de 45 $\mathrm{cm}$ entre si, utilizando-se semeadora modelo PAR 2800 regulada para distribuição de $300 \mathrm{~kg} \mathrm{ha}^{-1} \mathrm{da}$ fórmula NPK 00-20-20, na profundidade de 10 $\mathrm{cm}$, com população de 244.444 plantas ha ${ }^{-1}$. As cultivares utilizadas foram: a cultivar BRS 284 que é convencional, ciclo precoce, crescimento indeterminado, possui grupo de maturação 6.3, moderadamente resistente ao nematoide de galha Meloidogyne javanica e, a BRS 360 RR que é transgênica (tolerância ao herbicida glifosato. RR2 PRO TM), ciclo precoce, crescimento indeterminado, possui grupo de maturação 6.2 (EMBRAPA, 2013).

As sementes foram tratadas com fipronil e tiofanato-metílico, ambos na dose de $1 \mathrm{~g}$ i. a. por $\mathrm{kg}$ semente e inoculadas com Bradyrhizobium japonicum (100 $\mathrm{ml}$ para $50 \mathrm{~kg}$ de sementes), e semeadas a $5 \mathrm{~cm}$ de profundidade. Para o controle de insetos-pragas foi realizado uma aplicação de flubendiamida $\left(120 \mathrm{ml}\right.$ i. a. ha $\left.{ }^{-1}\right)$ e para o controle de doenças foi realizada uma aplicação de trifloxistrobina e protioconazol (400 ml i. a. ha ${ }^{-1}$ ) em 11/11/2014.

A maturação fisiológica da soja ocorreu em 26/01/2015 quando realizou-se a coleta das plantas em 2 linhas de $3 \mathrm{~m}$ de comprimento, espaçadas por $0,45 \mathrm{~m}$, utilizando-se colheitadeira de parcela (wintersteiger), para a determinação dos componentes de produtividade (número de grãos por plantas (NG planta ${ }^{-1}$ ), massa de 100 grãos (M 100) e produtividade $\left(\mathrm{kg} \mathrm{ha}{ }^{-1}\right)$, utilizando-se para o cálculo, a correção da umidade para $13 \%$.

Os dados foram submetidos à análise de variância, e quando significativos pelo teste $F$, as médias foram comparadas pelo teste de Tukey $(p \leq 0,05)$, utilizando-se o software SISVAR.

\section{Resultados e Discussão}

Atributos químicos do solo

A análise de variância indicou efeito de interação entre cultivos de outono-inverno e profundidades do solo para todas as características avaliadas, exceto para fósforo $(P)$ e ferro (Fe). No entanto, houve efeito isolado de profundidades do solo para fósforo $(\mathrm{P})$ e ferro (Fe). 
Figura 2. Acidez $(\mathrm{pH})$ e capacidade de troca de cátions (CTC) no solo em função dos cultivos de outono-inverno (B- Brachiaria ruziziensis; $\mathrm{M}$ Milho safrinha; $M+B$ - Consórcio milho $+B$. ruziziensis e C- feijão-caupi) e em relação as profundidades de solo durante o ano agrícola 2014/15 em Dourados, MS; DMS= Diferença Mínima Significativa.
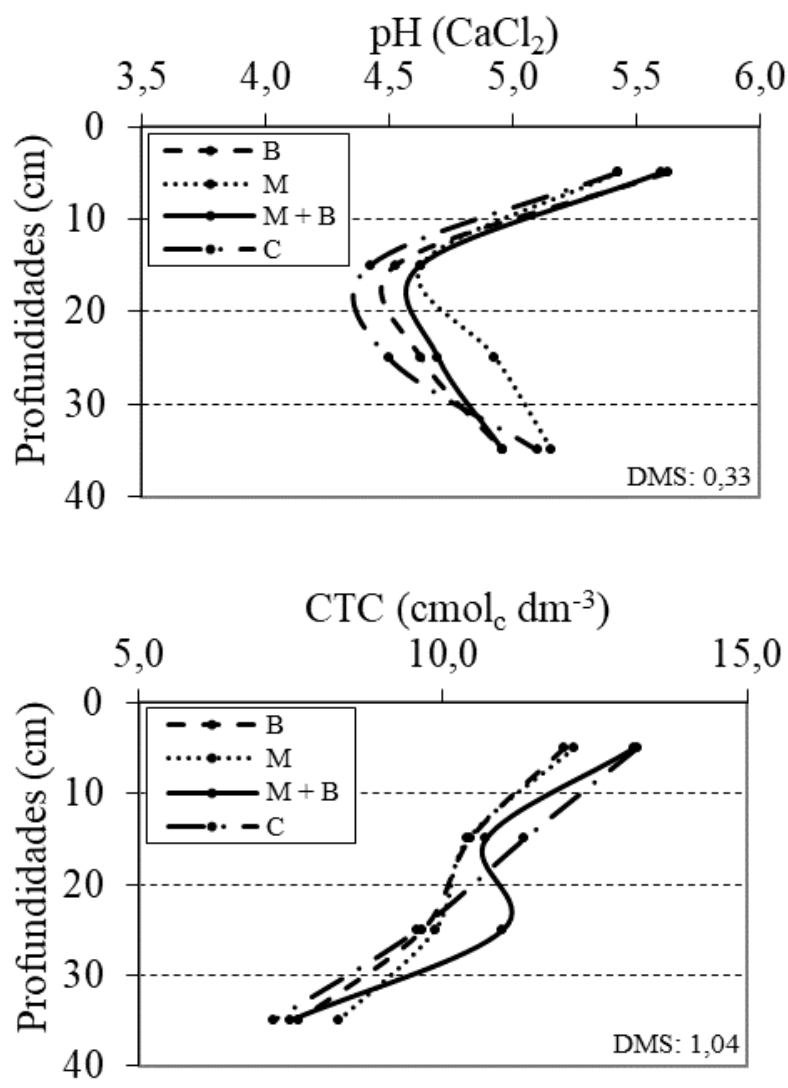

Com a observação da Figura 2, a profundidade de 0 a $10 \mathrm{~cm}$ apresentou $\mathrm{pH}$ entre 5,4 a 5,6, de modo geral entre os cultivos de outono inverno. Com os resultados obtidos neste trabalho, pode-se inferir que $\mathrm{o} \mathrm{pH}$ nessa profundidade possuiu valores considerados bons, de acordo com Raij et al. (1996) o pH em profundidades superficiais pode ser considerado alto dentro de um faixa entre 5,7 a 5,8 (Figura 2). $A$ área do experimento recebeu corretivo na dose de $3 \mathrm{Mg} \mathrm{ha}{ }^{-1}$ de calcário na época de 2008 e $1 \mathrm{Mg}$ $\mathrm{ha}^{-1}$ de gesso agrícola em 2013, com a finalidade de aumento da saturação de bases a $60 \%$, o que poderia explicar o aumento do $\mathrm{pH}$ na profundidade de $20 \mathrm{~cm}$ até a superfície. Para Caires (2003) os efeitos desses corretivos podem persistir na superfície do solo por longos períodos, entre 18 a 35 meses, em profundidades de até $10 \mathrm{~cm}$ e, neste experimento, contribuindo para a correção do $\mathrm{pH}$.
Com relação a CTC, a profundidade de 0 a $10 \mathrm{~cm}$ proporcionou os maiores valores, porém os cultivos como $\mathrm{C}$ e $\mathrm{M}+\mathrm{B}$ apresentaram o mesmos valores com 13,2 $\mathrm{cmol}_{\mathrm{c}} \mathrm{dm}^{-3}$ (Figura 2). $\mathrm{O}$ acúmulo de palha pelas culturas em SPD pode favorecer a liberação e disponibilidade de nutrientes importantes, melhorando as condições químicas do solo nas profundidades superficiais de forma eficiente (FIGUEIREDO et al., 2007). Os cultivos como $\mathrm{C}$, favorece os valores de matéria orgânica do solo pela rápida decomposição dos resíduos vegetais, devido a baixa relação $\mathrm{C} / \mathrm{N}$, que transforma esses resíduos vegetais em húmus, contribuindo com a CTC do solo (BISSANI et al., 2008). Já em relação ao $M+B$, é responsável pela maior produção de palha devido a soma das duas culturas, que consequentemente a uma maior disponibilidade de nutrientes havendo assim, uma melhor manutenção da CTC do solo (SANTOS et al., 2008).

Figura 3. Saturação por bases (V\%) e matéria orgânica (MO) no solo em função dos cultivos de outono-inverno (B- Brachiaria ruziziensis; $\mathrm{M}$ Milho safrinha; $M+B$ - Consórcio milho $+B$. ruziziensis e C- feijão-caupi) e em relação as profundidades de solo durante o ano agrícola 2014/15 em Dourados, MS; DMS= Diferença Mínima Significativa.
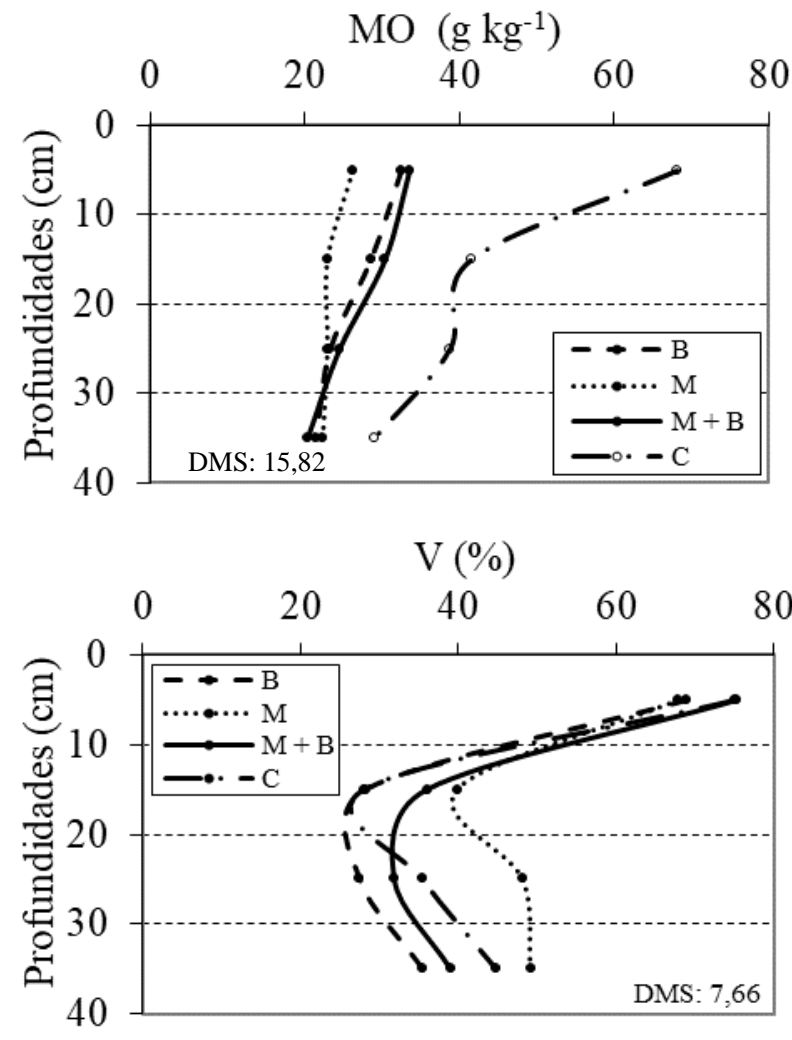
Para a MO, observou-se que a profundidade de 0 a $10 \mathrm{~cm}$ apresentou os maiores valores, independente do tipo de cultivo, porém, o $C$ apresentou superioridade em relação aos outros cultivos com $68,1 \mathrm{~g} \mathrm{~kg}^{-1}$ de MO (Figura $3)$, já os demais cultivos apresentaram valores próximo entre 26,3 a 33,6 $\mathrm{g} \mathrm{kg}^{-1}$. Cultivos de outono-inverno em SPD podem favorecer a MO devido ao aporte de resíduos vegetais sobre a superfície e em profundidade pelas raízes (SEREIA, 2014). O cultivo C apresenta decomposição rápida dos resíduos vegetais devido a baixa relação $C / N$, dessa forma podendo se decompor em até $62 \%$ do total de sua palha em apenas 90 dias, contribuindo assim com a disponibilidade de nutrientes (AZEVEDO; SPEHAR, 2002). Os valores da MO do solo na profundidade de 0 a $10 \mathrm{~cm}$ se comportaram de forma semelhante aos valores da CTC na mesma profundidade (Figura 2). Para Garay et al. (2003) a matéria orgânica fornecida pelos cultivos pode proporcionar incrementos a CTC, os autores ainda salientam que a $\mathrm{MO}$ e a CTC possuem uma estreita ligação. Trabalhos realizados por Costa et al. (2015) demonstram que sistemas de produção como a ILP em SPD, mesmo com alta taxa de exportação de nutrientes, foram eficientes para manutenção e melhoria da fertilidade e dos estoques de carbono do solo ao longo de três anos, além disso esse sistema também promoveu o incremento da macroporosidade e porosidade total em camadas de 0 a $20 \mathrm{~cm}$. Araujo et al. (2019) demonstraram que o consórcio de milho com leguminosas como feijão-caupi em SPD apresentaram aumento do carbono da biomassa microbiana e quociente microbiano semelhantes aos valores do solo em condições naturais de reserva, em profundidades de 0 a $10 \mathrm{~cm}$, os autores ainda salientam que a biomassa microbiana do solo mostraram-se sensíveis as modificações decorrentes ao tipo do sistema de consórcio.

Em relação ao V\%, os cultivos apresentam maiores valores na profundidade de 0 a $10 \mathrm{~cm}$, acima de 60\%, de acordo com Sereia (2014) valores a cima de $60 \%$ são considerados bons em profundidades superficiais (Figura 3), porém os cultivos $\mathrm{C}$ e $\mathrm{M}+\mathrm{B}$ apresentaram as mesmas porcentagens de $\mathrm{V} \%$, com $75,2 \%$, seguidos do $\mathrm{M}$ com $68 \%$. Em SPD, o V\% pode ser influenciado pela liberação de nutrientes como $\mathrm{Ca}, \mathrm{K}$ e $\mathrm{Mg}$ em profundidades superficiais devido a $\mathrm{MO}$, recorrente da maior cobertura vegetal que esse sistema proporciona (MARQUES et al., 1999).
Sereia (2014) explica que a diversidade de cultivos com sistemas radiculares profundos, podendo atingir até $1 \mathrm{~m}$ de profundidade em SPD, podem explorar as profundidades subsuperficiais e desclocar os nutrientes para a superfie disponibilizando-os por meio da decomposição dos resíduos vegetais. Porém, o cultivo $\mathrm{C}$ pela rápida decomposição em relação aos outros cultivos, contribui mais com o V\% pela liberação dos nutrientes, no entanto, cultivos como $\mathrm{M}+\mathrm{B}$ podem manter os padrões químicos do solo muito próximos aos adequados para o plantio, provavelmente devido ao maior aporte de material vegetal em superfície e profundidade pelas raízes (SEREIA, 2014).

Figura 4. Fósforo $(P)$ e potássio $(K)$ no solo em função dos cultivos de outono-inverno (BBrachiaria ruziziensis; $M$ - Milho safrinha; $M+B-$ Consórcio milho $+B$. ruziziensis e C- feijão-caupi) e em relação as profundidades de solo durante o ano agrícola 2014/15 em Dourados, MS; DMS= Diferença Mínima Significativa.
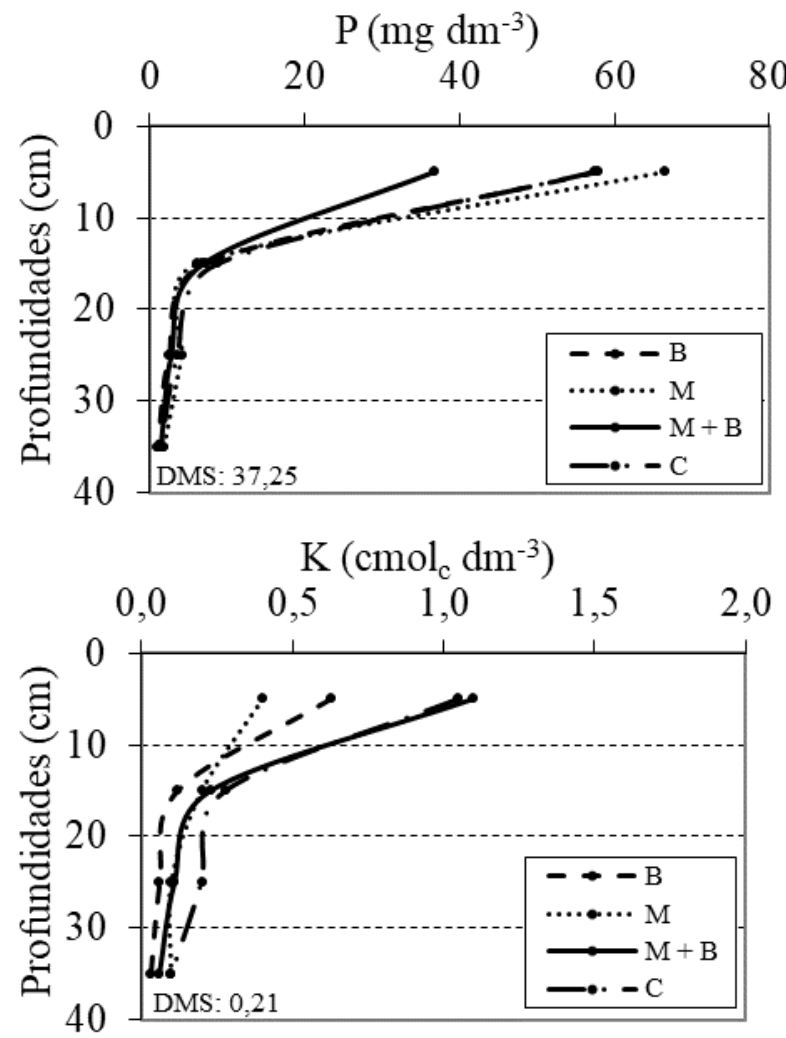

Os maiores valores de $\mathrm{P}$ foram observados na profundidade de 0 a $10 \mathrm{~cm}$ (Figura 4), esses resultados corroboram com os de Sereia (2014) onde os maiores valores de $P$ também foram observados nas profundidades superficiais após cultivos de outono inverno. No entanto, o cultivo $\mathrm{M}$ apresentou $\mathrm{O}$ maior valor de $\mathrm{P}$ com 
$66,60 \mathrm{mg} \mathrm{dm}^{-3}$, seguido do $\mathrm{C}$ com $57,56 \mathrm{mg} \mathrm{dm}^{-3}$. Para Sá (1993), com o passar dos anos de implantação de SPD, ocorre um acúmulo de $\mathrm{P}$ na superfície do solo decorrente da decomposição dos resíduos vegetais, os autores ainda salientam que isso é devido a baixa mobilidade desse nutriente no solo. Porém, o cultivo $M$ pode ser considerado um sistema conservacionista quando usado em SPD, tendo como características a disponibilidade de nutrientes pela decomposição primeiramente das folhas, dessa forma podendo favorecer a produtividade das culturas em sucessão (CRUZ et al., 2015). Já o C pode favorecer a ciclagem de $P$ por meio da decomposição de sua fitomassa (FERREIRA et al., 2011).

Com relação ao $K$, observou-se maiores valores na profundidade superficial de 0 a $10 \mathrm{~cm}$, independente do tipo de cultivo (Figura 4). Sereia (2014) explica que isso ocorre devido a maior presença dos resíduos vegetais e raízes das plantas remanescentes na profundidade superficial e, que no processo de decomposição liberam primeiramente o $\mathrm{K}$ para o ambiente. No entanto, os cultivos C e $M+B$ apresentaram os mesmos valores e os maiores de $\mathrm{K}$ em relação aos outros cultivos com $1,1 \mathrm{cmol}_{\mathrm{c}} \mathrm{dm}^{3}$. Esses cultivos como $\mathrm{C}$ e $\mathrm{M}+\mathrm{B}$ contribuem com o $\mathrm{K}$ liberado ao solo, devido a decomposição dos seus resíduos de um ano para o outro, chegando a $80 \%$ para gramíneas e $90 \%$ para leguminosas, tendo assim importante papel na cilagem desse nutriente (SANTOS et al., 2008).
Figura 5. Cálcio (Ca) e magnésio $(\mathrm{Mg})$ no solo em função dos cultivos de outono-inverno (BBrachiaria ruziziensis; M- Milho safrinha; $\mathrm{M}+\mathrm{B}$ Consórcio milho $+B$. ruziziensis e $C$ - feijão-caupi) e em relação as profundidades de solo durante $o$ ano agrícola 2014/15 em Dourados, MS; DMS= Diferença Mínima Significativa.

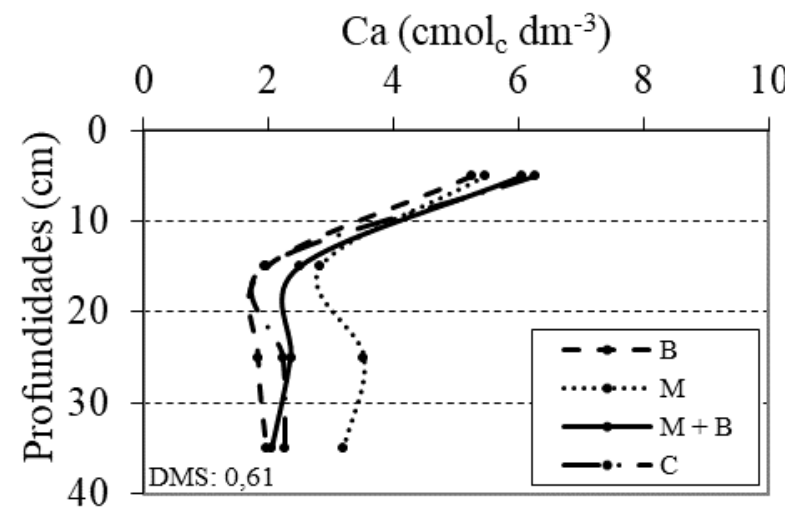

$\mathrm{Mg}\left(\mathrm{cmol}_{\mathrm{c}} \mathrm{dm}^{-3}\right)$

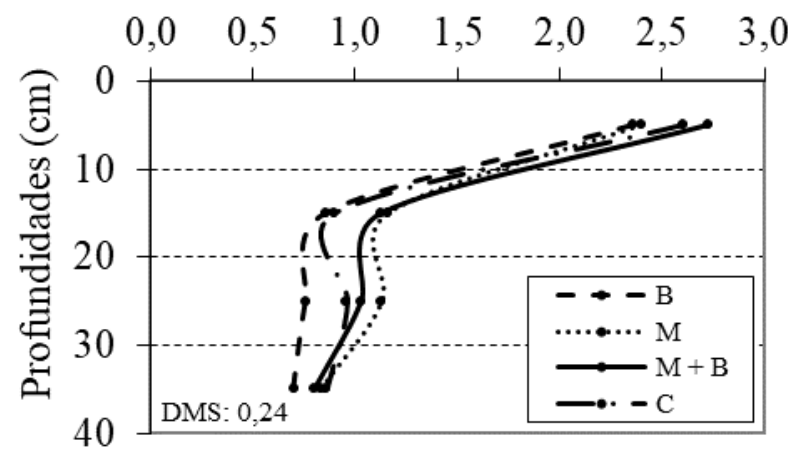

Para o Ca, observou-se que os maiores valores estão presentes na profundidade superficial, independete do tipo de cultivo, isso pode estar relacionado pela ciclagem desse nutriente pelas raízes das plantas (Figura 5). Pavani (1994) explica que as plantas promovem a migração de $\mathrm{Ca}$ em associação a outros nutrientes das profundidades subsuperficiais para a superfície do solo por meio de lacunas formadas pelas raízes. Entretanto, os cultivos como C e M + B apresentaram maiores valores de Ca em relação aos outros cultivos, com 6,3 e 6,1 $\mathrm{cmol}_{c} \mathrm{dm}^{3}$ respectivamente. $\mathrm{O} C$ tem a capacidade de acumular em sua massa seca, 18,3 $\mathrm{g} \mathrm{kg}^{-1}$ de Ca durante o seu cultivo e, com o processo de decomposição, esse nutriente é disponibilizado para o solo, promovendo a ciclagem desse nutriente (PEREZ et al., 2013). Já para Ceccon et al. (2009) o M + B apresenta a menor variação dos nutrientes no solo devido a sua quantidade de resíduos vegetais, nesse experimento podendo explicar o maior valor de Ca para esse cultivo. 
Com relação a $\mathrm{Mg}$, observou-se que os maiores valores apresentavam-se na profundidade superficial de 0 a $10 \mathrm{~cm}$, independente do tipo de cultivo (Figura 5), porém, cultivos como $\mathrm{M}+\mathrm{B}$ e $\mathrm{C}$ apresentaram os maiores valores de $\mathrm{Mg}$ com 2,7 e 2,6 $\mathrm{cmol}_{\mathrm{c}} \mathrm{dm}^{-3}$ respectivamente. Perez et al. (2013) explicam que cultivos como $\mathrm{C}$ podem acumular e disponibilizar com o processo de decomposição em torno de 4,5 a 4,8 $\mathrm{g} \mathrm{kg}^{-1}$ de $\mathrm{Mg}$ ao solo. Em relação ao $\mathrm{M}+\mathrm{B}$, o milho com $B$. ruziziensis, podem produzir maior quantidade de cobertura pela soma das duas culturas e, consequentemente a maior disponibilidade desse nutriente, havendo uma melhor manutenção nos atributos químicos do solo (SANTOS et al., 2008). No entanto, os teores de $\mathrm{Mg}$ pode variar dependendo da profundidade do solo, por meio da associação entre outros nutrientes ou por meio da lixiviação, mesmo sendo pouco móvel no solo (SOUSA; LOBATO, 2002).

Figura 6. Cobre $(\mathrm{Cu})$ e ferro $(\mathrm{Fe})$ no solo em função dos cultivos de outono-inverno (BBrachiaria ruziziensis; M- Milho safrinha; $\mathrm{M}+\mathrm{B}-$ Consórcio milho $+B$. ruziziensis e $C$ - feijão-caupi) e em relação as profundidades de solo durante 0 ano agrícola 2014/15 em Dourados, MS; DMS= Diferença Mínima Significativa.
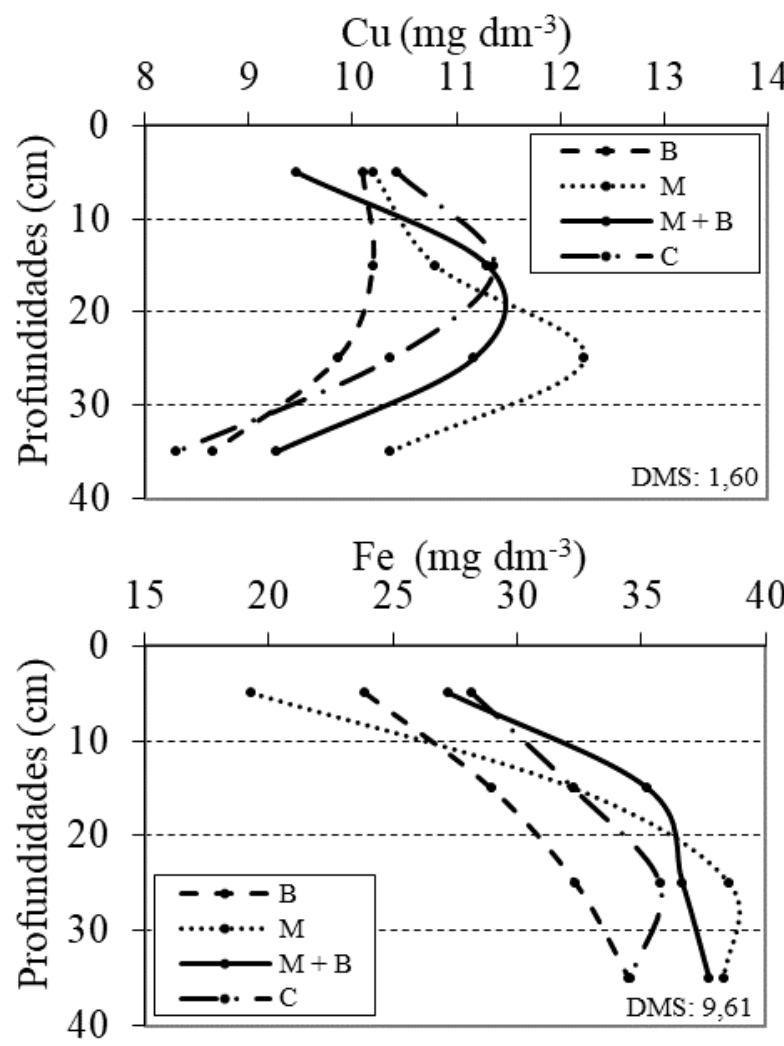

Com relação aos micronutrientes, os maiores valores de $\mathrm{Cu}$ foram observados em profundidades intermediárias de 10 a $30 \mathrm{~cm}$, independente do tipo de cultivo (Figura 6), no entanto o cultivo como $\mathrm{M}$ apresentou maior valor de $\mathrm{Cu}$ em relação aos outros nutrientes com 12,2 $\mathrm{mg} \mathrm{dm}^{-3}$. Esses maiores valores de $\mathrm{Cu}$ em profundidades intermediárias podem estar relacionados com a variação desse nutriente a sequência de culturas em SPD por meio do desenvolvimento radicular diversificado e, com o processo de decomposição disponibiliza $\mathrm{Cu}$ no subsolo (LOPES et al., 2004). Bissani et al. (2008) também explicam que o $\mathrm{Cu}$ é dependente da unidade de $\mathrm{pH}$, onde o acréscimo ou decréscimo da acidez pode promover ou reduzir micronutrientes como $\mathrm{Cu}$. Já o cultivo de $\mathrm{M}$ pode ser considerado um sistema conservacionista quando usado em SPD, tendo como características a disponibilidade e acúmulo de nutrientes ao solo, pela decomposição primeiramente das folhas (CRUZ et al., 2015).

Para o Fe, também observou-se de modo geral, maiores valores desse nutriente em profundidades no subsolo de 20 a $30 \mathrm{~cm}$, independente do tipo de cultivo (Figura 6), porém com o uso de $\mathrm{M}$ proporcionou maior valor de $\mathrm{Fe}$ com $38,6 \mathrm{mg} \mathrm{dm}^{-3}$ em profundidades de subsolo. De acordo com Bissani et al. (2008) não há uma sugestão de nível crítico de Fe disponível ao solo, já que não se tem constatado deficiências desse nutriente em plantas, os autores ainda salientam que alguns fatores que podem interferir na disponibilidade de $\mathrm{Fe}$ é a unidade de $\mathrm{pH}$ ou adubações fosfatadas, fazendo-se necessário o monitoramento para que os níveis estejam dentro do aceitável. 
Figura 7. Manganês ( $\mathrm{Mn}$ ) e zinco ( $\mathrm{Zn})$ no solo em função dos cultivos de outono-inverno (BBrachiaria ruziziensis; M- Milho safrinha; M + BConsórcio milho $+B$. ruziziensis e $C$ - feijão-caupi) e em relação as profundidades de solo durante 0 ano agrícola 2014/15 em Dourados, MS; DMS= Diferença Mínima Significativa.

Mn $\left(\mathrm{mg} \mathrm{dm}^{-3}\right)$
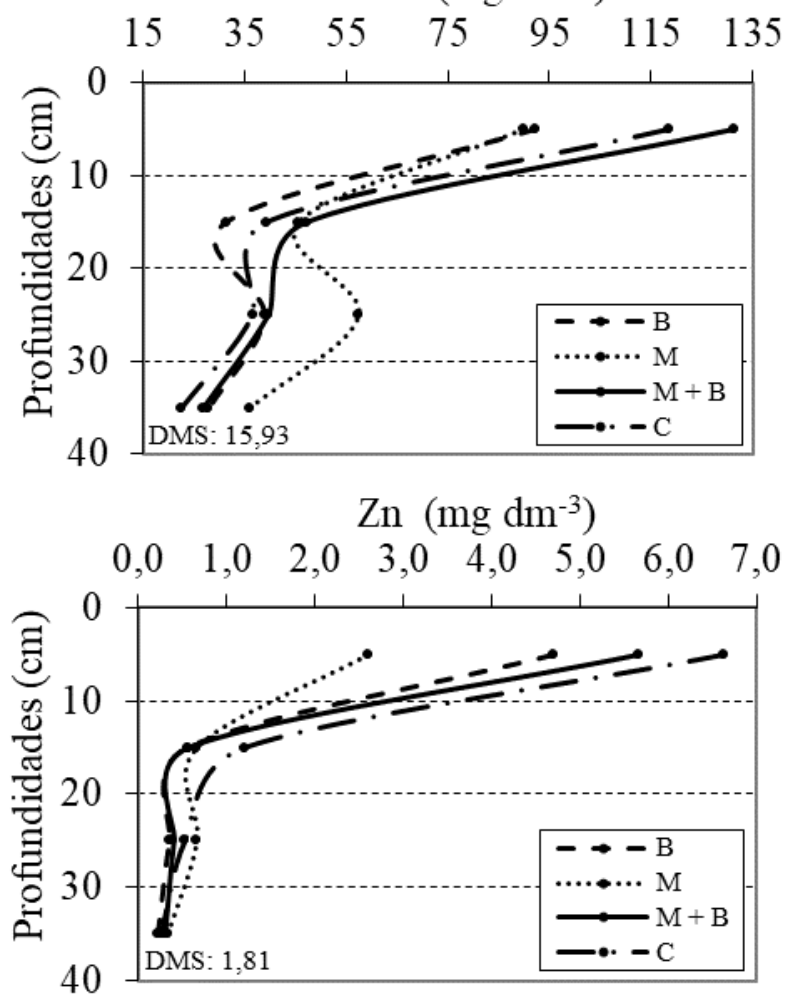

Os maiores valores de $\mathrm{Mn}$ foram observados na profundidade de 0 a $10 \mathrm{~cm}$, de modo geral para todos os cultivos (Figura 7), no entanto o cultivo $M+B$ proporcionou maiores valores de $\mathrm{Mn}$ com $131,4 \mathrm{mg} \mathrm{dm}^{-3}$, seguido do $C$ com 118,6 $\mathrm{mg} \mathrm{dm}^{-3}$. De acordo com Lopes et al. (2004) os maiores valores de $\mathrm{Mn}$ estão relacionados com a implantação do SPD, que devido a diversidade de culturas, pode pelo processo de decomposição liberar esse nutriente ao solo. Cavalcante et al. (2007) salientam que o não revolvimento do solo em SPD, também favorece os valores de $\mathrm{Mn}$ na superfície do solo. Já em relação ao cultivo $M+B$, esse pode acumular grandes quantidades de resíduos a superfície do solo e junto a alta densidade de raizes das duas culturas no mesmo local, favorecem após a dessecação a disponibilidade de Mn (MENDONÇA, 2012). Ceccon et al. (2013), salientam que o consórcio de milho com $B$. ruziziensis é importante pela manutenção da qualidade dos atributos físicos e químicos do solo, por outro lado o cultivo $\mathrm{C}$ pode disponibilizar entre 86,6 a $94,9 \mathrm{mg} \mathrm{kg}^{-1}$ de $\mathrm{Mn}$ a superfície do solo pelo processo de decomposição dos resíduos vegetais (PEREZ et al., 2013).

Com relação ao $\mathrm{Zn}$, observou-se maiores valores na profundidade de 0 a $10 \mathrm{~cm}$, de modo geral, variando entre 6,6 a $2,6 \mathrm{mg} \mathrm{dm}^{-3}$, independente do tipo de cultivo (Figura 7), no entanto os cultivos como $\mathrm{C}$ e $\mathrm{M}+\mathrm{B}$ apresentaram os maiores valores de $\mathrm{Zn}$ com 6,6 e 5,7 $\mathrm{mg} \mathrm{dm}^{-3}$ respectivamente. Para Perez et al. (2013) cultivos como $\mathrm{C}$ podem acumular em seus resíduos vegetais e disponibilizar após a decomposição em torno de 27,6 a $28,8 \mathrm{mg} \mathrm{kg}^{-1}$ de $\mathrm{Zn}$ ao solo. Já para o $M+B$, Ceccon et al. (2013) explicam que esse tipo de cultivo produz quantidades maiores de resíduos em comparação aos outros, dessa forma podendo proporcionar aumento na quantidade de $\mathrm{Zn}$ a superfície do solo pela mineralização de todo esse resíduo.

\section{Componentes de produtividade da soja}

A análise de variância indicou efeito de interação entre cultivos de outono-inverno e cultivares para número de grãos por planta (NG planta ${ }^{-1}$ ) e produtividade ( $\left.\mathrm{kg} \mathrm{ha}^{-1}\right)$. No entanto, houve efeito isolado de cultivares e de cultivos de outono-inverno para massa de cem grãos ( $M$ 100).

Observou-se diferença no NG planta $^{-1}$ entre as cultivares, onde a BRS 284 apresentou superioridade após cultivo em C com 163,64 (Tabela 1). Esses resultados podem estar relacionados com a uniformidade espacial entre plantas de uma cultivar, que podem influenciar os componentes de produtividade. Segundo Tourino et al. (2002) mesmo que as plantas estejam distribuídas uniformemente na área, ainda pode ocorrer competições intraespecíficas. Em relação ao cultivo $C$, esse possuí capacidade de contribuir com introdução de até $68 \mathrm{~kg} \mathrm{ha}^{-1}$ de $\mathrm{N}$ no solo através da fixação biológica de nitrogênio (CASTRO et al., 2004). 
Tabela 1. Número de grãos por planta (NG planta ${ }^{-1}$ ) das cultivares de soja BRS 284 e BRS 360 RR durante o ano agrícola 2014/15 após cultivos de outono-inverno (B- Brachiaria ruziziensis; M- Milho safrinha; M + BConsórcio milho + B. ruziziensis e C- feijão-caupi) em Dourados-MS.

\begin{tabular}{ccccc}
\hline \multicolumn{5}{c}{ NG planta $^{-1}$} \\
\hline Cultivares & B & M & M + B & C \\
\hline BRS 284 & $121,95 \mathrm{aB}$ & $130,29 \mathrm{aB}$ & $147,90 \mathrm{aAB}$ & $163,64 \mathrm{aA}$ \\
BRS 360 RR & $146,15 \mathrm{aA}$ & $141,44 \mathrm{aA}$ & $133,91 \mathrm{aA}$ & $136,38 \mathrm{bA}$ \\
Média & 134,05 & 135,87 & 140,91 & 150,01 \\
\hline C. (\%) & \multicolumn{5}{c}{17,33}
\end{tabular}

Médias seguidas de mesma letra minúscula na coluna e maiúscula na linha em cada variável, não diferem pelo teste de Tukey $(p<0,05)$.

A cultura da soja apresentou maior $\mathrm{M}$ 100 quando cultivada após $M$ com 8,42 , porém sem diferença estatística em relação ao $\mathrm{C}$ com 8,27 (Tabela 2). Isso pode estar relacionado pelos maiores valores de $\mathrm{P}$ em profundidades de 0 a 10 $\mathrm{cm}$, que esse cultivo apresentou em relação aos outros (Figura 4), outra explicação seria a proteção do solo que ele proporciona, pela durabilidade de sua palha e, quando usado em rotação de culturas pode ser considerado um sistema conservacionista, podendo até favorecer a produtividade da soja pelo acúmulo de nutrientes (BROCH; CECCON, 2008). Em contra partida, o cultivo $\mathrm{C}$ por pertencer a família Fabaceae, contribui com introdução de até $68 \mathrm{~kg}$ $\mathrm{ha}^{-1}$ de $\mathrm{N}$ no solo através da fixação biológica de nitrogênio (CASTRO et al., 2004), além de ter apresentado maiores valores de CTC, MO, $\mathrm{K}$ e Zn (Figuras 2, 3 e 7). Que neste experimento proporcionou condições favoráveis para a maior M 100.

Tabela 2. Massa de cem grãos (M 100) da soja durante o ano agrícola 2014/15 após cultivos de outonoinverno (B- Brachiaria ruziziensis; M- Milho safrinha; M + B- Consórcio milho + B. ruziziensis e C- feijãocaupi) em Dourados-MS.

\begin{tabular}{cc}
\hline Cultivos de outono-inverno & M 100 \\
\hline B & $7,20 \mathrm{bc}$ \\
M & $8,42 \mathrm{a}$ \\
$\mathrm{M}+\mathrm{B}$ & $6,94 \mathrm{c}$ \\
$\mathrm{C}$ & $8,27 \mathrm{ab}$ \\
Média & 7,71 \\
\hline C.V. (\%) & 15,24 \\
\hline
\end{tabular}

Médias seguidas de mesma letra na coluna, não diferem pelo teste de Tukey $(\mathrm{p}<0,05)$.

Com relação as cultivares, a soja BRS 360 RR apresentou maior $M 100$ com 9,10 em relação a BRS 284 com 6,31 (Tabela 3). A maior média produtiva da soja BRS 360 RR mostra que possivelmente houve uma maior adaptabilidade as condições edafoclimáticas da região de Dourados (MS), como por exemplo a maior sensibilidade ao fotoperíodo local. Para Kantolic (2008) a duração das fases e do ciclo de desenvolvimento da soja varia entre genótipos, mas é regulada pela sensibilidade ao fotoperíodo da região. 
Tabela 3. Massa de cem grãos (M 100) das cultivares de soja BRS 284 e BRS 360 RR durante o ano agrícola 2014/15 em Dourados-MS.

\begin{tabular}{cc}
\hline Cultivares & M 100 \\
\hline BRS 284 & $6,31 \mathrm{~b}$ \\
BRS 360 RR & $9,10 \mathrm{a}$ \\
Média & 7,71 \\
\hline C.V. (\%) & 15,24
\end{tabular}

Médias seguidas de mesma letra na coluna, não diferem pelo teste de Tukey $(p<0,05)$.

Para a produtividade $\left(\mathrm{kg} \mathrm{ha}^{-1}\right)$, observou-se de modo geral, que a cultivar BRS 360 RR apresentou maior média produtiva em relação a BRS 284 e, após cultivo em M com $2.210 \mathrm{~kg} \mathrm{ha}^{-1}$, no entanto sem diferença estatística após cultivo em B com $2.177 \mathrm{~kg} \mathrm{ha}^{-1}$ (Tabela 4). Ribeiro et al. (2018) também observaram que cultivares de soja geneticamente modificadas possuíram superioridade em produção à das cultivares convencionais. De acordo com Carmo et al. (2007) cultivares geneticamente modificadas possuem um maior potencial produtivo, devido aos programas de melhoramento, que por meio de seleção buscam cultivares por uma elevada estabilidade produtiva.

Já em relação aos cultivos de outonoinverno (Tabela 4), pode-se inferir que o $\mathrm{M}$ proporcionou melhores condições para a produtividade da soja possivelmente pelo maior valor de $\mathrm{P}$ em profundidades superficiais no solo (Figura 4). Segundo Luyandula e Hague (1992) e Giller et al. (1998) a nodulação em plantas leguminosas é influenciada pelo suprimento de $P$, podendo interferir positivamente no crescimento das plantas e na produtividade de grãos, quando há boa disponibilidade e quantidade desse nutriente no solo. Outra explicação seria a sua capacidade em reciclar consideráveis quantidades de nutrientes e libera-los de forma a suprir as necessidades nutricionais da soja, como o fósforo, cálcio e magnésio, principalmente quando usados em rotação de culturas (CRUZ et al., 2015). Em contra partida, a B cultivada solteira, é uma opção para formação de palha em plantio direto, devido a elevada produção de massa (NUNES et al., 2006), além da capacidade em manter a umidade na superfície do solo. Segundo Carneiro et al. (2014) a cobertura vegetal é responsável pela manutenção da umidade, pois a presença de água afeta o fluxo de calor no solo, que consequentemente controla a evaporação.

Tabela 4. Produtividade das cultivares de soja BRS 284 e BRS 360 RR durante o ano agrícola 2014/15 após cultivos de outono-inverno (B- Brachiaria ruziziensis; M- Milho safrinha; $\mathrm{M}+\mathrm{B}$ - Consórcio milho $+B$. ruziziensis e C- feijão-caupi) em Dourados-MS.

\begin{tabular}{ccccc}
\hline \multicolumn{5}{c}{ Produtividade $\left(\mathrm{kg} \mathrm{ha}^{-1}\right)$} \\
\hline Cultivares & $\mathrm{B}$ & $\mathrm{M}$ & $\mathrm{M}+\mathrm{B}$ & $\mathrm{C}$ \\
\hline BRS 284 & $1.583 \mathrm{bA}$ & $1.554 \mathrm{bA}$ & $988 \mathrm{bB}$ & $1.635 \mathrm{aA}$ \\
BRS 360 RR & $2.177 \mathrm{aA}$ & $2.210 \mathrm{aA}$ & $1.720 \mathrm{aB}$ & $1.813 \mathrm{aB}$ \\
Média & 1.880 & 1,882 & 1.354 & 1.724 \\
\hline
\end{tabular}

C.V. (\%) 15,19

Médias seguidas de mesma letra minúscula na coluna e maiúscula na linha em cada variável, não diferem pelo teste de Tukey $(p<0,05)$.

\section{Conclusões}

Os cultivos de outono-inverno antecedentes a soja em SPD, influenciaram os atributos químicos do solo em profundidades superficiais de 0 a $20 \mathrm{~cm}$.
Pronuncia-se 0 efeito dos cultivos antecessores de feijão-caupi, milho safrinha e $B$. ruziziensis nos componentes de produtividade da soja. 
A cultivar BRS 284 apresentou maior número de grãos por planta, no entanto a BRS 360 RR apresentou maior produtividade.

\section{Referências}

ARAUJO, T. S.; GALLO, A. S.; ARAUJO, F. S.; SANTOS, L. C.; GUIMARÃES, N. F.; SILVA, R. F. Biomassa e atividade microbiana em solo cultivado com milho consorciado com leguminosas de cobertura. Sociedade de Ciências Agrárias de Portugual, v.42, n.2, p.347-357, 2019. http://dx.doi.org/10.19084/rca.15433

AZEVEDO, D. M. P.; SPEHAR, C. R. Decomposição da palhada de culturas para plantio no período de safrinha em solos de tabuleiros costeiros. Teresina: Embrapa Meio Norte, 2002. (Comunicado Técnico, 147).

BALBINO, L. C.; CORDEIRO, L. A. M.; PORFIRIODA-SILVA, V.; MORAES, A.; MARTÍNEZ, G. B.; ALVARENGA, R. C.; KICHEL, A. N.; FONTANELI, R. S.; SANTOS, H. P.; FRANCHINI, J. C.; GALERANI, P. R. Evolução tecnológica e arranjos produtivos de sistemas de integração lavoura-pecuária-floresta no Brasil. Pesquisa Agropecuária Oeste, v.46, n.10, p.i-xii, 2011. http://dx.doi.org/10.1590/S0100204X2011001000001

BISSANI, C.; MEURER, E. J.; BOHNEN, H. Solos ácidos e solos afetados por sais. In: MEURER, E. J. Fundamentos de química do solo. Porto Alegre: Genesis, 2008. p.163-183.

BROCH, D. L.; CECCON, G. In: SEMINÁRIO NACIONAL DE MILHO SAFRINHA, 9. Produção de milho safrinha com integração lavoura e pecuária. Rumo à estabilidade. Anais [...]. Jun/2008. Disponível em: https://www.infoteca.cnptia.embrapa.br/bitstrea $\mathrm{m} / \mathrm{doc} / 254945 / 1 / 29902$.pdf Acesso em: $10 \mathrm{mar}$. 2019.

BRUGGEMANN, G. Estado da arte e divulgação do Plantio Direto no Brasil. Revista Plantio Direto, v.122, n.122, p.16-23, 2011.

CAIRES, E. F.; BLUM, J.; BARTH, G.; GARBUIO, F. J.; KUSMAN, M. T. Alterações químicas do solo e resposta da soja ao calcário e gesso aplicados na implantação do sistema plantio direto. Revista Brasileira de Ciência do Solo, v.27, n.2, p.275-
286, 2003. http://dx.doi.org/10.1590/S0100$\underline{06832003000200008}$

CARMO, S. L. M.; SANTOS, J. B.; HAGIWARA, W. E.; FERREIRA, J. L. Avaliação do 'stay green' em famílias segregantes de feijão (Phaseolus vulgaris L.). Ciência e Agrotecnologia, v.31, n.4, p.953957, 2007. http://dx.doi.org/10.1590/S1413$\underline{70542007000400002}$

CARNEIRO, M. A. C.; CORDEIRO, M. A. S.; ASSIS, P. C. R.; MORAES, E. S.; PEREIRA, H. S.; PAULINO, H. B.; SOUZA, E. D. Produção de fitomassa de diferentes espécies de cobertura e suas alterações na atividade microbiana de solo de cerrado. Bragantia, v.26, n.2, p.455-462, 2008. http://dx.doi.org/10.1590/S0006$\underline{87052008000200021}$

CARNEIRO, R. G.; MOURA, M. A. L.; SILVA, V. P. R.; SILVA JÚNIOR, R. S.; ANDRADE, A. M. D.; SANTOS, A. B. Variabilidade da temperatura do solo em função da liteira em fragmento remanescente da Mata Atlântica. Revista Brasileira Engenharia Agrícola e Ambiental, v.18, n.1, p. 99-108, 2014. http://dx.doi.org/10.1590/S1415$\underline{43662014000100013}$

COSTA, N. R.; ANDREOTTI, M.; LOPES, K. S. M.; YOKOBATAKE, K. L.; FERREIRA, J. P.; PARIZ, C. M.; BONINI, C. S. B.; LONGHINI, V. Z. Atributos do solo e acúmulo de carbono na integração lavoura-pecuária em sistema plantio direto. Revista Brasileira de Ciência do Solo, v.39, n.3, p.852-863, 2015. http://dx.doi.org/10.1590/01000683rbcs2014026 $\underline{9}$

CASTRO, C. M.; ALVES, B. J. R.; ALMEIDA, D. L.; RIBEIRO, R. L. D. Adubação verde como fonte de nitrogênio para a cultura da berinjela em sistema orgânico. Pesquisa Agropecuária Brasileira, v.39, n.8, p.779-785, 2004. http://dx.doi.org/10.1590/S0100204X2004000800008

CAVALCANTE, E. G. S.; ALVES, M. C.; SOUZA, Z. M.; PEREIRA, G. T. Variabilidade espacial de atributos químicos do solo sob diferentes usos e manejos. Revista Brasileira de Ciência do Solo, v.31, n.6, p.1329-1339, 2007. http://dx.doi.org/10.1590/S0100$\underline{06832007000600012}$ 
CECCON, G.; STAUT, L. A.; KURIHARA, C. H. Cerrado: Manejo de Brachiaria ruziziensis em consórcio com milho safrinha e rendimento de soja em sucessão. Revista Plantio Direto, v.113, n.113, p.4-8, 2009.

CECCON, G.; STAUT, L. A.; SAGRILO, E.; MACHADO, L. A. Z.; NUNES, D. P.; ALVES, V. B. Legumes and forage species sole or intercropped with corn in soybean-corn succession in Midwestern Brazil. Revista Brasileira de Ciência do Solo, v.37, n.1, p.204-212, 2013. http://dx.doi.org/10.1590/S010006832013000100021

CHIODEROLI, C. A.; MELLO, L. M.; GRIGOLLI, P. J.; FURLANI, C. E. A.; SILVA, J. O. R.; CESARIN, A. L. Atributos físicos do solo e produtividade de soja em 9 sistema de consórcio milho e braquiária. Revista Brasileira de Engenharia Agrícola e Ambiental, v.16, n.1, p.37-43, 2012. http://dx.doi.org/10.1590/S1415-

\section{5}

CONAB. Acompanhamento da safra brasileira. fev/2019. Disponível em: https://www.conab.gov.br/info-agro/safras

Acesso em: 10 abr. 2019.

COSTA, H. J. U.; JANUSCKIEWICZ, E. R.; OLIVEIRA, D. C.; MELO, E. S.; RUGGIERI, A. C. Massa de forragem e características morfológicas do milho e da Brachiaria brizantha cv. piatã cultivados em sistema de consórcio. Ars Veterinária, v.28, n.2, p.134-143, 2012.

CRUZ, J. C.; PEREIRA FILHO, I. A.; ALBUQUERQUE FILHO, M. R. In: AGEITEC- Agência Embrapa de Informação Tecnológica: Árvore do conhecimento "milho". Embrapa Informação Tecnológica. Dez/2015. Disponível em: https://www.agencia.cnptia.embrapa.br/gestor/ milho/arvore/CONT000fy779fnk02wx5ok0pvo4k3 s932q7k.html Acesso em: 31 dez. 2018.

EMBRAPA. Guia clima. Jan/2015. Disponível em: https://clima.cpao.embrapa.br/?lc=site/bancodados/construtor-basico Acesso em: $31 \mathrm{dez}$. 2015.

EMBRAPA. Embrapa apresenta cultivares de soja para safra 2013/2014 em MS. Jan/2013. Disponível em: https://www.embrapa.br/buscade-noticias/-/noticia/1471969/embrapa- apresenta-cultivares-de-soja-para-safra20132014-em-ms- Acesso em: 03 nov. 2018.

FERREIRA, E. P. B.; STONE, L. F.; PARTELLI, F. L.; DIDONET, A. D. Produtividade do feijoeiro comum influenciada por plantas de cobertura e sistemas de manejo do solo. Revista Brasileira de Engenharia Agrícola e Ambiental, v.15, n.7, p.695-701, 2011. https://www.researchgate.net/publication/2439 48693

FIGUEIREDO, C. C.; RESCK, D. V. S.; GOMES, A. C.; FERREIRA, E. A. B.; RAMOS, M. L. G. Carbono e nitrogênio da biomassa microbiana em resposta a diferentes sistemas de manejo em um Latossolo Vermelho no Cerrado. Revista Brasileira de Ciências do Solo, v.31, n.3, p.551-562, 2007. http://dx.doi.org/10.1590/S010006832007000300015

GARAY, I.; KINDEL, A.; CARNEIRO, R.; FRANCO, A. A.; BARROS, E.; ABBADIE, L. Comparação da matéria orgânica e de outros atributos do solo entre plantações de Acacia mangium e Eucalyptus grandis. Revista Brasileira de Ciência do Solo, v.27, n.4, p.705-712, 2003. http://dx.doi.org/10.1590/S0100$\underline{06832003000400015}$

GILLER, K.; AMIJEE, F.; BRODERICK, S.; EDJE, O. Environmental constraints to nodulation and nitrogen fixation of Phaseolus vulgaris $\mathrm{L}$. in Tanzania. II: Response to N and P fertilizers and inoculation with Rhizobium. African Crop Science Journal, v.6, n.2, p.171-178, 1998. http://dx.doi.org/10.4314/acsj.v6i2.27813

KANTOLIC, A. G. Control ambiental y genético de la fenologia del cultivo de soja: impactos sobre el rendimiento y la adaptación de genótipos. Revista da Facultad de Agronomía UBA, v.28, n.1, p.63-88, 2008.

LOPES, A. S.; WIETHÖLTER, S.; GUILHERME, L. R. G.; SILVA, C. A. Sistema plantio direto: bases para o manejo da fertilidade do solo. São Paulo: ANDA, 2004.

LUYANDULA, N.; HAGUE, I. Effect of Rhizobium and phosphorus on growth and nitrogen fixation in tree legumes grown in highland vertisols. In: MULONGOY, K.; GUEY, M.; SPENCER, D. S. C. Biological nitrogen fixation and sustainability of 
tropical agriculture. Wiley-Sayce, 1992. p.109112.

MARQUES, E. S.; FAQUIN, V.; GUIMARÃES, P. T. G. Teores foliares de nutrientes no cafeeiro (Coffea arábica L.) em resposta a calcário e gesso. Revista Ciência e Agrotecnologia, v.23, n.1, p.140-151, 1999.

MENDONÇA, V. Z. Consorciação de milho com forrageiras: Produção de silagem e palha para plantio direto de soja. 2012. Dissertação (Mestrado em Agronomia) - Universidade Estadual Paulista, Ilha Solteira, 2012.

NUNES, U. R.; JÚNIOR, V. C. A.; SILVA, E. B.; SANTOS, N. F.; COSTA, H. A. O.; FERREIRA, C. A. Produção de palhada de plantas de cobertura e rendimento do feijão em plantio direto. Pesquisa Agropecuária Brasileira, v.41, n.6, p.943-948, $2006 . \quad$ http://dx.doi.org/10.1590/S0100204X2006000600007

PAVANI, M. A. Movimentação de calcário no solo através de técnicas de manejo da cobertura vegetal em pomares de macieira. Revista Brasileira de Fruticultura, v.16, n.1, p.86-91, 1994.

PEREZ, A. A. G.; SORATTO, R. P.; MANZATTO, N. P.; SOUZA, E. F. C. Extração e exportação de nutrientes pelo feijoeiro adubado com nitrogênio, em diferentes tempos de implantação do sistema de plantio direto. Revista Brasileira de Ciências do Solo, v.37, n.5, p.1276-1287, 2013. http://dx.doi.org/10.1590/S010006832013000500017

RAIJ, V. B.; CANTARELLA, H.; QUAGGIO, J. A.; FURLANI, A. M. C. Recomendações de adubação e calagem para o estado de São Paulo. Campinas: Instituto Agronômico e Fundação IAC Brasil, 1996. (Boletim técnico, 100).

RIBEIRO, L. M.; CECCON, G.; MECHI, I. A.; SANTOS, A. L. F.; FACHINELLI, R.; MAKINO, P. A. Produtividade da soja em sucessão a cultivos de outono-inverno. Revista Agrarian, v.11, n.40, p.120-131, 2018. https://doi.org/10.30612/agrarian.v11i40.5379

SÁ, J. C. M. Manejo da fertilidade do solo no plantio direto. Castro: Fundação ABC, 1993.
SANTOS, F. C.; NEVES, J. C. L.; NOVAIS, R. F.; ALVAREZ, V. V. H.; SEDIYAMA, C. S. Modelagem da recomendação de corretivos e fertilizantes para a cultura da soja. Revista Brasileira de Ciência do Solo, v.32, n.4, p.661-1674, 2008. http://dx.doi.org/10.1590/S010006832008000400031

SANTOS, H. G.; JACOMINE, P. K. T.; ANJOS, L. H. C.; OLIVEIRA, V. A.; LUMBRERAS, J. F.; COELHO, M. R.; ALMEIDA, J. A.; ARAUJO FILHO, J. C.; OLIVEIRA, J. B.; CUNHA, T. J. F. Sistema brasileiro de classificação de solos. Brasília: Embrapa Solos, 2018.

SANTOS, V. A.; SILVA, C. A. O clima de Dourados (MS) e a proposição de um roteirometodológico simples para entender a poluição atmosférica de áreas urbanas. Revista Geonorte, v.3, n.5, p.969982, 2012.

http://www.periodicos.ufam.edu.br/revistageonorte/article/view/2159

SEREIA, R. C. Atributos físicos e químicos do solo sob cultivos de outono-inverno em sistema de semeadura direta. 2014. Dissertação (Mestrado em Agricultura) - Universidade Estadual Paulista "Júlio de Mesquita Filho", Botucatu, 2014.

SILVA, A. R.; SALES, A.; CARVALHO, E. J. M.; VELOSO, C. A. C. Dinâmica de sistemas integrados de manejo de um solo no desenvolvimento da cultura do milho. Revista em Agronegócio e Meio Ambiente, v.9, n.4, p.859-873, 2016. http://dx.doi.org/10.17765/21769168.2016v9n4p859-873

SILVA, F. C. Manual de análises químicas de solos, plantas e fertilizantes. Brasília: Embrapa Informação Tecnológica, 2009.

SOUSA, D. M. G.; LOBATO, E. Correção da acidez do solo. In: SOUSA, D. M. G.; LOBATO, E. Cerrado: correção do solo e adubação: Planaltina: Embrapa Cerrados, 2002. p.81-96.

TOURINO, M. C. C.; REZENDE, P. M.; SALVADOR, N. Espaçamento, densidade e uniformidade de semeadura na produtividade e características agronômicas da soja. Pesquisa Agropecuária Brasileira, v.37, n.8, p.1071-1077, 2002. http://dx.doi.org/10.1590/S0100$\underline{204 \times 2002000800004}$ 